\title{
Notas de pesquisa sobre questões de gênero na brincadeira do Bumba-meu-boi
}

Research notes on gender issues in "bumba-meu-boi"

Francisco Marcos Mendes Nogueira ${ }^{1}$

1 Universidade Federal do Rio Grande do Sul - UFRGS, E-mail: marcos2201@gmail.com, ORCID: https://orcid.org/0000-0002-1630-5613

ARTICLE INFO

Article history:

Received 2021-04-19

Accepted 2021-06-21

Available online 2021-06-21
Palavras-chave: Notas de Pesquisa. Gênero. Bumba-meu-boi. Cultura Popular.

Keywords: Research Notes. Gender. Bumba-meuboi. Popular culture.

RESUMO. O presente texto visa socializar breves impressões, em forma de notas, sobre questões de gênero na brincadeira do Bumba-meu-boi. Para isso, tomo como lugar de fala, análise e compressão a pesquisa desenvolvida, entre os anos de 2017 e 2020, por ocasião do meu doutorado em História, no Programa de Pós-graduação da Universidade Federal do Rio Grande do Sul (UFRGS), cuja Tese, defendida em janeiro de 2021, tem por título - "O bumba-meu-boi maranhense urrou em Roraima: a (re) produção de um território simbólico-cultural (1975-2019)" -. Vale registrar que, embora, no primeiro momento, o conceito de gênero não tenha sido elencado como chave principal para a leitura e a interpretação sociocultural do folguedo, ele acabou não passando desapercebido, especialmente por ordenar significados, práticas sociais e relações de poder de homens e mulheres dentro da brincadeira do bumbameu-boi de matriz maranhense. A metodologia da pesquisa com a abordagem qualitativa coligiu diferentes fontes: pesquisa de campo nos estados do Maranhão e Roraima, redes sociais (Instagram) dos principais grupos de Bois do Maranhão, bem como registros fotográficos e entrevistas semiestruturaras (gravadas em áudio/vídeo) e, posterior tratadas e analisadas como fontes de pesquisa. Por fim, o texto aponta que, hodiernamente, as mulheres têm conquistado espaço e visibilidade, mas ainda persiste a mentalidade machista para determinar os melhores papéis sociais e culturais, além da objetificação do corpo da mulher por meio da feminilidade e sensualidade.

ABSTRACT. This text aims to socialize brief impressions, in the form of notes, about gender issues in the Bumba-meu-boi game. For this, I take as a place of speech, analysis and compression the research developed, from 2017 to 2020, on the occasion of my doctorate in History, in the Postgraduate Program of the Federal University of Rio Grande do Sul (UFRGS), whose Thesis, defended in January 2021, is entitled "The maranhense bumba-meu-boi roared in Roraima: the (re)production of a symbolic- 
cultural territory (1975-2019)" -. It is worth noting that, although, at first, the concept of gender was not listed as the main key to the reading and sociocultural interpretation of revelry, it ended up not going unnoticed, especially for ordering meanings, social practices and power relations of men and women in the game of bumba-meu-boi from Maranhão matrix. The research methodology with a qualitative approach gathered different sources: field research in the states of Maranhão and Roraima, social networks (Instagram) of the main groups from Maranhão, as well as photographic records and semi-structural interviews (recorded in audio/video) and, later treated and analyzed as research sources. Finally, the text points out that, nowadays, women have conquered space and visibility, but the macho mentality still persists to determine the best social and cultural roles, in addition to objectifying the woman's body through femininity and sensuality.

\section{Introdução}

"Na rede de relações sociais que caracterizam os grupos de Bumba, percebe-se a existência de uma particular 'divisão do trabalho', com papéis e funções definidos na dinâmica da brincadeira”

CARVALHO, 1995, p. 75-76.

O presente texto é um breve recorte da minha Tese de Doutorado1" "O bumbameu-boi maranhense urrou em Roraima: a (re) produção de um território simbólicocultural', defendida junto ao Programa de Pós-graduação em História, da Universidade Federal do Rio Grande do Sul (PPGH/UFRGS). Ressalto que, no primeiro momento, as questões de gênero, na Tese, não era o foco central ou, muito menos, o objeto de análise. Entretanto, ao longo da pesquisa de campo, especialmente, nos estados do Maranhão e Roraima, entre os anos de 2017 a 2020, tais questões começaram a "saltar" aos olhos e a se desvelar a partir das práticas e dos significados de gênero, no que se refere a demarcar os espaços de homens e mulheres dentro dos grupos ou na própria brincadeira de bumba-meu-boi ${ }^{2}$.

Foi a partir dessa perspectiva, mencionada anteriormente, que acabei por incluir na Tese um tópico sobre questões de gênero na brincadeira Bumba-boi, mesmo reconhecendo que o tema exige um maior aprofundamento e debate, singularmente porque a brincadeira é considerada tipicamente masculina, à vista disso, as mulheres

\footnotetext{
${ }^{1}$ Sob a orientação da Prof. ${ }^{\text {a }}$ Dr..$^{\text {a }}$ Regina Weber

${ }^{2}$ No Maranhão a brincadeira é conhecida por Bumba-meu-boi, Bumba-boi ou simplesmente Boi.
} 
são colocadas em serviços secundários ou percebidas como "cuidadoras" através dos serviços de cozinha, bordado etc. Essa visão, de acordo com Lima e Albernaz (2013), se deu como uma construção a partir da restrição e limitação das mulheres no Bumbameu-boi.

Mesmo com toda a "invisibilidade", Albernaz (2010) advoga que mulheres sempre estiveram presentes. Entretanto, devido a sua cor e classe social, elas acabam ficando anônimas na história do Bumba-boi ou quando muito era chamadas por "mutucas"3"

Desta feita, o texto versa sobre as questões de gênero a partir da empiria do pesquisador, das leituras de Scott (1995), Carvalho (1995; 2003), Albernaz (2010), Lima, Oliveira, Albernaz (2012) e Lima e Albernaz (2013) e, concomitante, em diálogo com as fontes produzidas ou coletas no decorrer da pesquisa de campo entre os anos de 2017 a 2020. Por fim, busquei demostrar que, embora, as mulheres tenham conquistados espaços e visibilidade no interior das brincadeiras do bumba-meu-boi, ainda persiste a mentalidade machista e, em grande medida, a objetificação do corpo da mulher por meio da feminilidade e sensualidade, em particular com a personagem "Índia”.

\section{Procedimentos metodológicos}

A estratégia metodológica adotada foi de caráter qualitativo, na qual procurei perceber as questões de gênero na brincadeira do Bumba-meu-boi a partir da pesquisa de campo nos estados do Maranhão e Roraima, entre os anos de 2017 a 2020, além de utilizar de outras fontes, como: orais, redes sociais (Instagram) e o registro fotográfico.

Como sinalizei, a pesquisa de campo aconteceu nos estados do Maranhão e de Roraima e a motivação/seleção desses dois estados se deu por cauda da temática da minha tese. Ou seja, a brincadeira do Boi de matriz maranhense no Extremo Norte tem sua ligação/relação com a migração de maranhenses para Roraima nos idos dos anos de 1970. A despeito da brincadeira no estado roraimense, mesmo tendo

\footnotetext{
3 De acordo com a explicação dos nossos interlocutores as mulheres eram chamadas de "mutucas" porque elas ficavam vigiando ou cuidado os maridos ou namorados quando iam para as brincadeiras. Essa referência estava ligada a uma figura de linguagem para comparar a condição da mulher as das moscas que ficam "importunando" o gado enquanto pasta
} 
proximidade com o estado Amazonas, os migrantes do Maranhão buscam manter o bumba-meu-boi por meio da (re)construção de um território simbólico-cultural ${ }^{4}$.

Isso posto, a escolha dos sujeitos colaboradores para as entrevistas não vislumbrou critérios probabilísticos, mas a partir do entendimento da sua representação como sujeito social e cultural que tem um envolvimento afetivo e efetivo com o folguedo do boi. Por essa razão, além desse envolvimento, tonou-se, também, como critério de inclusão para as fontes orais a anuência da participação pessoal por meio da assinatura do Termo de Consentimento Livre e Esclarecido (TCLE) e da Cessão Gratuita dos Direitos de Entrevista Gravada em Áudio/Vídeo.

Alessandro Portelli $(1997$, p. 36) reforça que as fontes orais não são um fim em si mesmo, mas uma mediação na construção de conhecimentos. Desse modo, as "fontes orais são fontes orais". Por esta razão, "as histórias narradas amealham vozes revividas e constelações de imagens, enredando os fios da existência", conforme reforçaram Amauri Carlos Ferreira e Yonne de Souza Grossi (2004, p. 42).

Já nas redes sociais, optei por pesquisar no Instagram dos principais grupos de bumba-meu-boi maranhense, dentre eles: o Boi de Nina Rodrigues, Boi de Morros, Boi Pirilampo, Boi da Lua e o Boi de Axixá. O lócus, aqui mencionado, serviu de fonte para analisar como a questão de gênero é retratada e divulgada nas redes socias dos grupos de bumba-meu-boi.

E, por fim, e não menos importante, no decorrer investigativo na pesquisa de campo, buscou-se fazer os registros fotográficos. Sobre o uso de imagens, Milton Guran (2000, p. 160 2012) discorre que sua particularidade se dá pela capacidade de revelar "aspectos da realidade", que, por vezes, encontram-se diluídos na vastidão do campo de visão das pessoas.

Outrossim, a fotografia tem o potencial de "congelar" a fração do tempo em que o objeto ou pessoa foi fotografada, por essa razão, o autor observa que sua matéria-prima é a face visível da realidade que se processa incessantemente como movimento constante. Assim, pensar a fotografia é, antes de tudo, reconhecer que ela tem um valor a partir de determinada cena fotografa/registrada. Por consequência a imagem remete a lembrança daquilo que se faz relembrar através do "recorte" ou "congelamento" do tempo.

\footnotetext{
${ }^{4} \mathrm{~A}$ este respeito, eu convido os leitores a conhecer um pouco mais a partir da minha tese de doutorado que se encontra disponível no Repositório Digital da UFRGS, no sítio <https://lume.ufrgs.br/>.
} 


\section{Desenvolvimento}

$\mathrm{Na}$ pesquisa original, já mencionada ao longo do texto, a perspectiva de gênero não estava prevista e nem era a minha intenção, a priori, discutir o tema, pois na minha cabeça estava que eu queria era perceber como os sujeitos, localizados no Extremo Norte, reproduziam o território simbólico-cultural tendo como mote o bumbameu-boi de matriz maranhense. No entanto, com o desenvolvimento da pesquisa, o aprofundamento das leituras sobre o tema e a sistematização e a análise dos dados, chamou atenção para as questões de gênero que sobressaiam, seja no Maranhão como em Roraima. Dessa forma, discussão acabou fazendo parte da Tese.

Assim, a discussão a seguir versará sobre questões de gênero na brincadeira do Bumba-meu-boi. Antes, porém, vale a pena situar, para aos menos familiarizados do Bumba-meu-boi maranhense, visto que, o boi é percebido e aceito como representação identitária da maranhecidade e do próprio Maranhão (LIMA, 1982; ALBERNAZ, 2004; PRADO, 2007; REIS, 1984 e 2009; CARVALHO, 2011). Essa relação, em certa medida, pode ser associada à dimensão cultural, social e votiva/religiosa que se faz presente na brincadeira do boi.

A dimensão votiva/religiosa, no entendimento, dos nossos interlocutores e corroborado com as produções acadêmicas em que afirmam que são os Santos Católicos (Santo Antônio, São João, São Pedro e São Marçal) os que "verdadeiramente" comandam a brincadeira do bumba-meu-boi. É a partir desse entendimento, tanto das fontes orais como as acadêmicas e/ou de memorialistas, que afirma haver um ciclo festivo e ritualístico, a saber:

a) No Sábado de aleluia ocorrem os primeiros ensaios do Boi. Neste dia são apresentadas as toadas (músicas) que farão parte das apresentações públicas;

b) No dia de Santo Antônio (13 de junho) é feito o ensaio redondo;

c) O batizado do Boi, de acordo com a tradição o boi só pode brincar publicamente depois do ritual do batizado 5 no dia 23 de junho. O ritual serve para consagrar o "animal" a São João e, ao mesmo tempo, receber do Santo a permissão para brincar;

d) Ritual da Morte, alguns grupos de Bumba-meu-boi, no estado do Maranhão, fazem o ritual no dia 26 de julho, por ocasião da Festa em honra à Sant'Ana,

\footnotetext{
${ }^{5} \mathrm{O}$ ritual segue os mesmos preceitos e ritual do batizado da Igreja Católica. Nele há a presença dos padrinhos. No estado do Maranhão o ritual é conduzido por padres da Igreja Católica ou pelos próprios padrinhos.
} 
contudo, não há uma única data para este ritual. Não obstante, os grupos fazem entre os meses de agosto e outubro.

Posto isso, seguem-se agora com as notas de pesquisa sobre as questões de gênero na brincadeira do Bumba-meu-boi. Para isso, concordo com Joan Scott, (1995, p. 75) quando afirmou que o conceito de gênero "[...] torna-se uma forma de indicar 'construções' - a criação inteiramente social de ideais sobre os papéis adequados aos homens e às mulheres". Ou seja, essas construções socioculturais não são naturais ou biologicamente determinantes, elas são definidas a partir das relações sociais e culturais.

Relações que podem ser vistas nas próprias brincadeiras a partir das toadas ou da forma como o grupo é mencionado, sendo que é predominantemente masculino uma vez que, na maioria das vezes a forma mais presente de chamamento aos brincantes por "vaqueiros", "rapaziadas", "moçada" ou, ainda, "companheiros". Por consequência, Oliveira e Albernaz (2013) discorrem que o Bumba-meu-boi, pode ser considerado tipicamente masculino e, acaba por classificar as práticas de gêneros.

Para se entender melhor essa classificação, no Maranhão, de um modo geral, a brincadeira de bumba-meu-boi é mais masculina do que feminina, "[...] sendo os homens aparecem como símbolo de força e poder e as mulheres de beleza e sensualidade" (LIMA; OLIVEIRA; ALBERNAZ, 2012, p. 183-184). Por essa razão, Albernaz $(2010$, p. 91) afirma que,

"[...] as mulheres supostamente podem ser qualquer personagem dentro do grupo, seja do auto ou do cordão. Entretanto, o lugar da índia se sobressai, pelas suas implicações quanto ao gênero e porque existe uma forma corporal que cristaliza a mulher como representação do belo"

Essa cristalização foi percebida por mim, especialmente, quando pesquisei o Instagram dos principais grupos, conforme apresenta as imagens abaixo onde há o destaque da personagem Índia do Boi de Nina Rodrigues e do Boi de Axixá (FIGURA 1). 

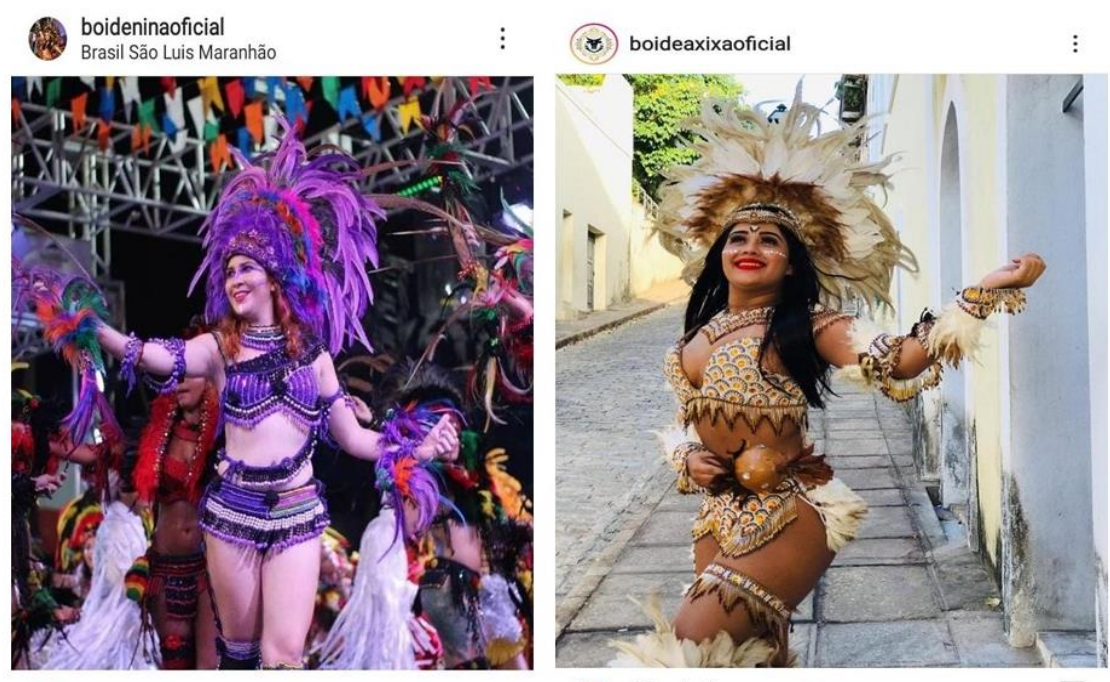

० $\nabla$

๑

ఐ

Figura 1 - Índias do Boi de Nina Rodrigues e do Boi de Axixá (MA)

Fonte: www.instagram.com/boideninaoficial; www.instagram.com/boideaxixaoficial

Para além dessa fetichização do corpo da mulher para classificar as questões de gênero e, ao mesmo tempo, determinar o melhor lugar para as mulheres nos grupos de Bumba-meu-boi. A brincadeira, no Maranhão, tem por demarcação a racialização e o gênero, conforme destacaram Lima e Albernaz (2013).

Quadro 1- Sotaques do Bumba meu boi do Maranhão por gênero e racialização

\begin{tabular}{|l|c|c|}
\hline \multicolumn{1}{|c|}{ Sotaques/Região } & $\begin{array}{c}\text { Classificação de } \\
\text { Gênero }\end{array}$ & Racialização \\
\hline Sotaque Ilha ou de Matraca & Masculina & Mestiços \\
\hline Sotaque de Guimarães ou de Zabumba & Masculina & Negros \\
\hline Sotaque da Baixada ou Pindaré & Neutra & Negros \\
\hline Sotaque de Orquestra & Feminina & Brancos \\
\hline
\end{tabular}

Fonte: Adaptado pelo autor a partir de Lima e Albernaz, 2013.

A brincadeira do folguedo do boi é encontrada em vários estados do País. No entanto, essa nomeação, Sotaque, só foi encontrado no estado do Maranhão. Em Roraima, os grupos pesquisados, Boi Douradinho, no município de Alto Alegre; Boi Estela do Vale, no município de Boa Vista; e, o Boi Rei Brilhante, no município de Mucajaí, são conhecidos pelo Sotaque ligado à questão geográfica. Ou seja, a influência é o Sotaque de Matraca. 
Dos grupos de boi existente no estado de Roraima chama atenção que somente um tem uma mulher como Mestra e Ama do Boi, o Boi Rei Brilhante. De acordo com Armandina Di Manso o processo de aceitação não foi fácil devido a sua condição de mulher, "hoje em dia é que eles [os homens] começam a me ver com outros olhos., mas no início foi complicado" (DI MANSO, 2017).

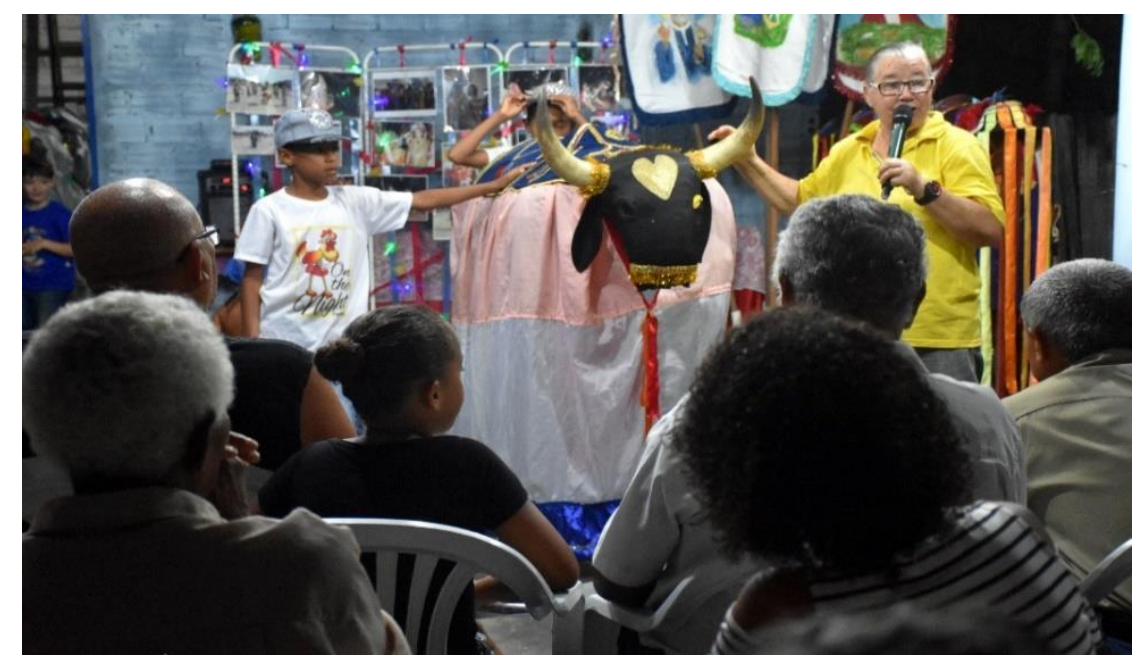

Foto 1 - Armandina Di Manso: Mestra e Ama do Grupo de Boi Rei Brilhante Foto: Acervo do próprio autor, 2018.

O convívio, por ocasião da pesquisa de campo e das entrevistas com a nossa narradora, me permite inferir que a sua aceitação dentro do grupo foi uma conquista pessoal e não foi algo imposto, especialmente quando ela afirma que, "somente agora é que começam a me respeitar". Talvez seja, por essa razão, das dificuldades de ser aceita, é que Armandina, enquanto Mestre e liderança, busca incentivar e motivar para que outras mulheres possam ter vez e espaço dentro do folguedo.

\section{4. À guisa de considerações finais}

A pesquisa mostrou como as questões de gênero se impõem e saltou aos olhos deste pesquisador, especialmente com a pesquisa de campo nos estados supracitados. Foi a partir da pesquisa-participante, das entrevistas e do aprofundamento das leituras que as questões de gênero foram visibilizadas por mim, pois as representações sociais, naturalizam as desigualdades de gênero.

É notório que as poucas laudas deste texto não permitiram um aprofundo maior e mais complexo sobre o tema. Isso significa dizer que, se faz necessário ainda mais ampliarmos o debate, pois, não obstante as mulheres tenham conseguido 
avançar nas conquistas de direitos e participação sociocultural, seu protagonismo por vezes é colocado em segundo plano frente a imposição do machismo e do patriarcado dentro das culturas populares e da própria brincadeira do Bumba-meu-boi.

\section{Referências}

ALBERNAZ, Lady Selma Ferreira. O "Urrou" do Boi em Atenas: instituições, experiências culturais e identidades no Maranhão. Tese (Doutorado em Ciências Sociais) - Universidade Estadual de Campinas, Instituto de Filosofia. São Paulo, 2004, $346 \mathrm{f}$.

ALBERNAZ, Lady Selma Ferreira. Mulheres e cultura popular: gênero e classe no Bumba-meu-boi maranhense. In: Revista Maguaré. Universidade Nacional de Colômbia. (Bogotá) n. 24, 2010, p. 69-98.

ALBERNAZ, Lady Selma Ferreira. Dinâmicas do Bumba meu boi maranhense: classificação em "sotaques" e a participação do público. In: Revista Olhares Sociais. v. 2, n. 2, 2013, p. 3-24.

CARVALHO, Maria Michol Pinho de. Matracas que desafiam o tempo: é o bumbaboi do Maranhão um estudo da tradição/modernidade na cultura popular. São Luís/MA: [s.n], 1995.

CARVALHO, Maria Michol Pinho de. As mulheres no Bumba-meu-boi: saindo detrás das cortinas. In: Olhar, memória e reflexões sobre a gente do Maranhão. São Luís/MA: Comissão Maranhense de Folclore, 2003, p. 69-72.

FERREIRA, Amauri Carlos.; GROSSI, Yonne de Souza. A narrativa na trama da subjetividade: perspectiva e desafios. In: Revista da Associação Brasileira de História Oral, n. 7, jun., Rio de Janeiro: ABHO, 2004.

GURAN, Milton. Fotografar para descobrir, fotografar para contar. In: Cadernos de Antropologia e imagem. v. 10, n. 1, 2000, p. 155-165.

LIMA, Carlos de. Bumba-meu-boi. 3aㅡ ed. São Luís, 1982.

LIMA, Patrícia Georgia de; ALBERNAZ, Lady Selma Ferreira. Gênero e cultura popular: relações de poder, posições e significados da participação das mulheres nos grupos de Bumba-meu-boi. In: Revista Sociais e Humanas. Santa Maria/RS, v. 26, n. 03, set/dez, 2013, p. 489-508.

LIMA, Patrícia Georgia de; OLIVEIRA, Jailma Maria; ALBERNAZ, Lady Selma Ferreira. Maracatu e Bumba-meu-boi: onde estão as mulheres?. In: Revista Intratextos, Rio de Janeiro, 4 (1), 2012, p. 181-200.

SCOTT, Joan. Gênero: uma categoria útil de análise histórica. In: Educação \& Realidade. 20 (2), jul./dez., 1995, p. 71-99. Disponível em: $<$ https://seer.ufrgs.br/educacaoerealidade/article/view/71721/40667>. Acesso em: 03 de abri. de 2018.

PORTELLI, Alessandro. O que faz a história oral diferente. (Trad.) Maria Therezinha Janine Ribeiro. In: Projeto História, São Paulo (14), Fevereiro, 1997.

PRADO, Regina de Paula Santos. Todo ano tem: as festas na estrutura social camponesa. São Luís/MA: EDUFMA, 2007.

REIS, José Ribamar Sousa dos. Bumba-meu-boi: o maior espetáculo popular do Maranhão. 2ed. Recife: Editora Massanga, 1984.

REIS, José Ribamar Sousa dos. Folguedos \& Danças Juninas do Maranhão. São Luís/MA: EDUFMA, 2009. 